[PAULA RAFAELA DA SILVA]

Doutoranda na PUCRS com bolsa de financiamento Capes. Pesquisadora no Grupo História da Arte e Cultura de Moda ligado à UFRGS.

E-mail: paula.rafaela@gmail.com

\title{
0 sagrado e 0 profano no museu: uma mediação através da moda
}

The sacred and profane: mediation by fashion

Heavenly Bodies: Fashion and the Catholic Imagination

Curadoria: Andrew Bolton

Local e periodo: Metropolitan Museum of Arts and Costume Institute (MET), Nova York (Estados Unidos). De 10 de maio a 8 de outubro de 2018. 
A exposição Heavenly Bodies: Fashion and the Catholic Imagination (Corpos sagrados: moda e a imaginação católica), realizada pelo Metropolitan Museum of Arts and Costume Institute (MET) em Nova York, de 10 de maio a 8 de outubro de 2018, teve como objetivo promover a reflexão sobre o diálogo entre moda, religião e arte'. A mostra esteve pautada em três elementos principais: trajes assinados por renomados estilistas que tiveram inspiração na arte sacra, a coleção de arte medieval do MET e peças raras do Museu do Vaticano, cedidas exclusivamente para a exibição.

0 curador e idealizador da exposição, Andrew Bolton², formado pela University of East Anglia, é chefe curador do MET desde 2006, ano em que deixou o Victoria and Albert, onde atuou durante nove anos. Ele é reconhecido por sua capacidade de conseguir manter o rigor acadêmico, ainda que suas exposições sejam marcadas pela extravagância e teatralidade. "Eu nunca tive hierarquia para valores culturais" (BOLTON apud TREBAY, 2015) ${ }^{3}$, afirma o curador, que também foi responsável pelas exibições Alexander McQueen: Savage Beauty e China: Through the Looking Glass ${ }^{5}$, ambas explorando o diálogo entre moda e arte.

Católicos vivem em um mundo encantado, um mundo de estátuas e água benta, velas coloridas e votivas, santos e medalhas religiosas, rosários bentos e pinturas sagradas. Mas toda essa parafernália são meros indícios de uma sensibilidade religiosa mais profunda e difusa que inclina os Católicos a ver o santo na criação (GREELEY apud BOLTON, 2018, p. 95) .

Em Heavenly Bodies, Bolton manteve as características pelas quais se tornou conhecido: um grande e belo espetáculo que possibilita o diálogo entre o contemporâneo e a coleção do museu. A exposição priorizou 0 contraste entre os artefatos da arte medieval e bizantina do MET e os tecidos cuidadosamente modelados por nomes como Jonh Galiano, Alexander McQueen, Karl Lagerfeld, Yves Saint Laurent, Gianni Versace entre outros célebres criadores.

Sob o ponto de vista da indumentária, a mostra não apresentou uma narrativa cronológica. As roupas contemporâneas foram dispostas por temáticas de maneira triunfal, gerando um grande impacto no público devido à composição com a iluminação, a música que tocava nos ambientes e o bem explorado clima medieval das salas do MET.

Inicialmente, ao caminhar pelo corredor de acesso já era possivel visualizar a interação entre as roupas e as peças do museu, pois artefatos de estilo bizantino - que são de exposição permanente - tinham a intervenção de manequins que vestiam produções Versace e Dolce \&t Gabbana. Nesse ambiente o dourado era a cor predominante nas roupas, os mane- 
quins estavam dispostos acima da altura do público, criando um ambiente de "anunciação", unindo elegância, imaginação e fé.

Seguindo então por peças inspiradas pelos ex-votos de estilistas como Elsa Schiaparelli e Jean-Paul Gaultier e a cruzes de ouro de Christian Lacroix, o visitante chegava a duas imponentes imagens de Maria localizadas na altura do olhar e no centro do salão de entrada para a galeria principal. Uma Nossa Senhora vestia Ricardo Tisci (presente para As Pobres Freiras Beneditinas Cassinesi de Lecce) e outra Yves Saint Laurent (presente para a Catedral de Notre Dame).

Ambas remetiam à questão dos presentes oferecidos pelos fiéis a Maria, como agradecimento pelas preces atendidas. Essa prática, que teve início na Idade Média, e o uso dos vestidos belos e requintados nas estátuas de tamanho real deixavam a Mãe de Deus ainda mais humana e, portanto, mais mulher. Por isso, a prática oferecia aos fiéis recursos visuais que permitiam associar a roupa às características morais da Santa e ao corpo feminino de uma mulher comum e de moral idônea. Também vale destacar que a imagem de Nossa Senhora é predominante nos vitrais das galerias do MET que remetem à Idade Média.

0 ponto alto da exposição, no que se refere às peças de alta-costura, estava na galeria principal de arte da Idade Média do museu${ }^{7}$. Primeiro, pela potência do espaço que reproduz o interior de uma igreja medieval em tamanho real ${ }^{8}$; depois, pela maneira como as roupas foram distribuídas neste espaço, possibilitando uma série de reflexões.

Nas laterais, havia vestidos que foram inspirados em hábitos de monges, padres e freiras, nos quais o preto reina fazendo menção à simplicidade. Chanel, Ricardo Tisci e Dolce \& Gabbana são os nomes de destaque. 0 branco também aparece nos trajes que lembram figuras santas, como é o caso da peça da casa A. F. Vandevorst, inspirada em Santo Agostinho e contrastada com a obra que mostra cenas da vida do santo e sua ascensão hierárquica dentro da igreja, o que leva também à modificação da sua indumentária9 .

Ao centro da galeria, antes do portão medieval, enfileiradas, estavam três peças luxuosas que causavam grande impacto. Da maneira como estavam dispostas, as peças lembravam papas em diferentes momentos. Uma das peças era de Alexander McQueen para Givenchy, com predominância do preto e volumes em renda; esta era seguida por um Pierpaolo Piccioli para Valentino, em que o tafetá vermelho impressionava pela aparente simplicidade unida à sensualidade do decote. De acordo com o catálogo (BOLTON, 2018), essa peça pode ser remetida tanto às vestes de um cardeal ou de um papa. Isso é demonstrado através do óleo sobre cobre de Ottavio 
Leoni com título de A Procissão do Cardeal, de 1621. E, também, pelo traje da Anunciação demonstrado no painel de óleo na madeira de Robert Campin numa peça de altar de cerca de 1427-1432.

A terceira peça, a mais luxuosa de todas, era também a mais inquietante: uma versão do traje papal de festa feito por John Galliano para Christian Dior (outono/inverno 2000-2001), em que o dourado predomina de forma impositiva, juntamente com um corpo estruturado, de cintura marcada. Chamou-me atenção, justamente, que o manequim que vestia este traje fosse o único com corpo masculino no salão. Isso é digno de nota, levando em conta que diversos trajes dos estilistas eram justamente a apropriação de vestes masculinas, ligadas a santos e autoridades eclesiásticas, para corpos femininos - corpos femininos "pagãos".

A força desta composição, na qual o único "homem" do salão estava posto em frente ao "portal da igreja" de maneira tão deslumbrante, não deixa dúvidas do quanto a indumentária é uma potente ferramenta cultural, sendo capaz de impressionar e apaixonar quem fica diante da exuberância expressa em tecidos, cores e adornos.

Dessa forma, entendo que, no conjunto, existe um contraste entre os trajes da alta costura e a iconografia do periodo medieval. Isso deixa claro que, nesta época, mulheres e homens com menor função hierárquica tiveram seus corpos cobertos com trajes largos, desprovidos de cor e sensualidade, para transmitir conceitos atrelados ao "povo de deus". Dentre eles a virtude e a modéstia, sobretudo para as mulheres. É algo diferente do que ocorre nos altos escalões, cujos integrantes, além de vestirem trajes em cores vibrantes como vermelho, roxo e dourado, também utilizavam joias e acessórios para adornar o corpo e para representar a encarnação da autoridade máxima da fé católica: o Deus Pai.

Mas, simbolicamente, é na galeria com o nome da editora chefe da Vogue estadunidense - Anna Wintour - que os visitantes tinham contato com o tamanho do luxo e da demonstração do poder da Igreja. Peças de valor incalculável, pertencentes ao Museu do Vaticano e cedidas para a exposição, compunham o elo de ligação entre as pinturas de arte sacra do acervo do MET e as criações/apropriações dos grandes nomes da moda mundial.

Peças com histórias repletas de contradições e, ao mesmo tempo, extremamente belas. Tecidos com pinturas feitas à mão por artistas reconhecidos, bordados com fios de ouro, pedras preciosas em grande quantidade e em diferentes tamanhos, causavam enorme impacto nos visitantes porque eram, indiscutivelmente, ainda mais chamativos do que as peças da alta-costura distribuídas pelas galerias do museu. 
Dentre as relíquias ${ }^{10}$ cabe destacar algumas peças que pertenceram a pontífices. Primeiro, do acervo que pertenceu ao Papa Pio IX (13/5/1792 7/2/1878), uma Tiara - ou Mitra Alta - que foi presenteada pela Rainha Isabella II da Espanha em reparação às leis anticlericais do Estado Espanhol. A peça, datada de 1854, tem aproximadamente 19 mil pedras preciosas, sendo a maioria delas diamantes. A Tiara, que foi usada pelo próprio Pio IX pela primeira vez em 1854 na Basilica de São Pedro para a Missa de Natal, carrega com ela todo o poder político exercido pelo pontífice que foi um atuante líder dos interesses da Igreja.

Outras peças que mereceram destaque foram o presente de Benito Mussolini para o Papa Pio Xl, e que também levanta uma reflexão em relação à política, visto que o primeiro-ministro italiano e o pontífice foram os responsáveis pelo Acordo de Latrão"1. A Mitra presenteada ao Papa Pio XI feita em seda branca, com bordados em fio de ouro, aplicação de ametistas e símbolos católicos esculpidos à mão em prata - foi utilizada para selar a ligação entre a Igreja e Estado.

Ainda do Papa Pio Xl, outro item merece ser comentado justamente pelo paradoxo: uma Casula ${ }^{12}$ em seda dourada, também bordada com fios de ouro e de seda, em que figuras humanas são perfeitamente esculpidas pelas linhas e narram, na parte do corpo, cenas da vida de São Francisco de Assis e, na região do pescoço, uma cena de Maria, Mãe de Deus, festejando junto a anjos e santos a proclamação do Dogma de Nossa Senhora da Imaculada Conceição.

A Casula, datada de 1926, foi um presente da Ordem dos Frades Menores em comemoração aos 700 anos da morte de São Francisco de Assis. No entanto, quem fez a peça foram as Pobres Irmãs de Clara do Monastério de Santa Clara de Mazamet (França), uma congregação que exige clausura e voto de pobreza. Dessa forma, podemos pensar que, historicamente, essa peça carrega o paradoxo da riqueza e beleza, tendo sido esculpida e produzida por mãos pobres e sem acesso ao que construiam, questão que é carissima para a moda na atualidade.

Inegavelmente, as peças do Vaticano tornaram a exposição ainda mais intrigante. Através delas é possivel levantar questões referentes à relação da Igreja com a indumentária e também da relação do sagrado com a organização social e o poder político. Diante daquelas roupas e acessórios, é impossivel não questionar o quanto o sagrado, através da Igreja, ainda é vigente em nossos dias, influenciando e atuando sobre os sentimentos relacionados aos corpos e suas ocupações sociais.

E esse, talvez, tenha sido o ponto mais questionado pela crítica, que esperava uma maior problematização dessas contradições (VALENTINE, 
2018). Contudo, mesmo que a problematização desses paradoxos não tenha aparecido como ponto central da proposta - ou que ele possa, eventualmente, enganar o espectador pelo viés da beleza das peças -, entendo que, ainda assim, ele atua no ambiente das galerias. As informações dos espaços forneciam ferramentas para que um espectador ligeiramente informado e interessado pudesse saber mais sobre o tema.

Penso sempre o espaço do museu como uma escola que, como tal, deve promover o diálogo entre as temporalidades para que tenha sentido. $E_{1}$ embora as roupas de alta-costura ainda possam ser consideradas uma questão polêmica para a academia sob o ponto de vista artístico (BRANDÃO, 2017), não se pode ignorar o diálogo que a moda vem promovendo nas últimas décadas com os mais diversos tipos de manifestações e espaços de arte. De modo que, para além da apropriação vulgar (HEARTNEY, 2018), é necessário que se reflita sobre a maneira como cada tempo se narra historicamente, e isso passa inevitavelmente por dialogar com o passado.

A despeito de Rihanna vestida de Papisa ${ }^{13}$, do baile glamoroso de ingressos carissimos reverberar justamente a construção social presente na exposição, penso ser necessário e urgente que se vá além. É preciso refletir sobre como se dá a relação de poder desses corpos que, modelados por vestes, permanecem regendo e criando normas sociais. É importante reconhecer e compreender esse potente "dicionário" visual católico cristão, pois somente assim poderemos desconstruí-lo. 


\section{NOTAS}

${ }^{1}$ A exibição pode ser vista na sede central do MET em NY e no Met Cloisers. Esta resenha é baseada nas peças presentes na sede central, visto que não foi possivel visitar o mosteiro.

${ }^{2}$ Para a exposição, Andrew Bolton contou com a parceria da Versace - que comemora 40 anos em 2018 - e com o apoio da editora Condé Nast.

${ }^{3}$ Tradução da autora para: "I've never been one to have a hierarchy of cultural values".

${ }^{4}$ Nova York: Metropolitan Museum of Arts and Costume Institute, 4 de maio a 7 de agosto de 2011, e Londres:Victoria and Albert Museum, 14 de março a 2 de agosto de 2015. Essa exposição foi um fenômeno de público e privilegiou as categorias visuais desenvolvidas pelo estilista, que faleceu jovem deixando um verdadeiro legado para a moda (PRESS ASSOCIATION, 2015).

${ }^{5}$ Nova York: Metropolitan Museum of Arts Costume Institute, 7 de maio a 7 de setembro de 2015.

${ }^{6}$ Tradução da autora para: "Catholics live in an enchanted world, a world for statues and holy water, stained and votive candles, saints and religious medals, rosary beads and holy pictures. But these Catholic paraphernalia are mere hints of a deeper and more pervasive religious sensibility which inclines Catholics to see the Holy lurking in creation."

${ }^{7}$ Mapa do andar térreo do MET disponivel em: https://maps.metmuseum.org. Acesso em: 9 ago. 2018.

${ }^{8}$ A galeria 305 a qual refiro no texto é, por si só, um dos espaços mais imponentes do MET. Além de esculturas e rica iconografia medieval, a galeria apresenta a reprodução interna de uma igreja do século XVIII e conta com um portão original de ferro datado de 1763, que servia para separar o altar dos fiéis. Para saber mais, ver: https://www.metmuseum.org/art/collection/search/201926. Acesso em: 5 ago. 2017.

${ }^{9}$ Trata-se de Master of Saint Augostine of Hippo (Netherlandish, circa 1490) - óleo, ouro e prata em madeira - The Cloisters Collection, 1961.

${ }^{10}$ Refiro-me a relíquia como objetos raros e de valor. Neste caso, objetos que tiveram contato com corpos que carregam a santidade de liderança da igreja.

${ }^{11} 0$ Tratado de Latrão criou o Estado do Vaticano reconhecendo o papa como seu Chefe de Estado. Além de indenizar a Igreja por parte do território de Roma que passou a pertencer à Itália, o tratado também oficializou o catolicismo como religião oficial do pais. Recentemente, o tratado foi revisto pelos chefes de Estado e, atualmente, a Itália é um Estado laico.

${ }^{12}$ A Casula é uma veste litúrgica cujas cores variam conforme o rito. Simboliza o "Planeta" por sua forma arredondada, que eleva o sacerdote do mundo terreno para o Espiritual.

${ }^{13}$ Refiro-me ao Met Gala que é um evento beneficente cujo intuito é arrecadar recursos para o Costume Institute do Metropolitan Museum of Art. É tradicionalmente feito no início do mês de maio, conta com a presença de importantes celebridades e marca a abertura da exposição do instituto. Cada ano o baile conta com uma "rainha" para recepcionar os convidados - em 2018 foi Rihanna - e a temática da exposição é o que rege os trajes de gala. Rihanna recepcionou os convidados vestida de Papisa e o traje curto com muito brilho, acompanhado da Mitra como acessório, foi entendido como uma crítica ao machismo da lgreja que só delega seus cargos mais alto para homens.

\section{REFERÊNCIAS}

BOLTON, Andrew. Catalogue Heavenly Bodies: Fashion and the Catholic Imagination. New York: The MET, 2018.

BRANDÃO, A. Uma história de roupas e de moda para a história da arte. MODOS. Revista de História da Arte. Campinas, v. 1, n.1, p. 40-55, jan. 2017. Disponivel em: http://www.publionline.iar. unicamp.br/index.php/mod/article/view/728. Acesso em: 3 ago. 2018.

HEARTNEY, Eleanor. The Met's 'Heavenly Bodies' Show Mines Catholicism for Eye Candy, and the Result Is Both Gorgeous and Unsettling. Artnet Worldwide Corporation, 10 maio 2018. Disponivel em: https://news.artnet.com/exhibitions/heavenly-bodies-fashion-and-the-catholicimagination-1282631. Acesso em: 3 ago. 2018.

PRESS ASSOCIATION. Alexander McQueen: Savage Beauty is most popular show in VEA's history. The Guardian, 3 ago. 2015. Disponivel em: https://www.theguardian.com/fashion/2015/aug/03/ alexander-mcqueen-show-savage-beauty-most-popular-victoria-and-albert-history. Acesso em: 3 ago. 2018.

TREBAY, Gay. At the Met, Andrew Bolton Is the Storyteller in Chief. The New York Times, 29 abr. 2015. Disponivel em: https://www.nytimes.com/2015/04/30/fashion/mens-style/at-the-metandrew-bolton-is-the-storyteller-in-chief.html. Acesso em: 3 ago. 2018.

VALENTINE, Genevieve. Heavenly Bodies' Is Gorgeous - But Full Of Strange Silences. NPR Book Review, 2 jun. 2018. Disponivel em: https://www.npr.org/2018/06/02/613155526/heavenly-bodiesis-gorgeous-but-full-of-strange-silences. Acesso em: 2 ago. 2018. 